\title{
Nonepileptic Paroxysmal Events (NEPE) in Children
}

\author{
Ranga Chetana ${ }^{1} \cdot$ Vykuntaraju K. Gowda $^{2}$ (D) Sanjay K. Shivappa ${ }^{1}$
}

Received: 23 May 2021 / Accepted: 5 August 2021 / Published online: 1 September 2021

(c) Dr. K C Chaudhuri Foundation 2021

To the Editor: Nonepileptic paroxysmal events (NEPE) are sudden, involuntary changes in behavior, sensation, motor activity, cognition or autonomic function linked to a dysfunction in the processing of psychological or social distress. Frequently mistaken for epilepsy at onset in $10 \%-20 \%$ of the patients, NEPE are costly to patients and society and their diagnosis is usually delayed [1]. Hence, this study was planned with an objective to evaluate the spectrum of NEPE and usefulness of home videos in identification of NEPE. Children aged less than $18 \mathrm{y}$ from January 2018 to June 2019 were included. NEPE were diagnosed based on detailed clinical history, examination, home video, interictal EEG, and video EEG recordings.

Of total 2130 children with paroxysmal events, 193/2130 (9\%) were NEPE. Mean age of presentation was $5.7 \mathrm{y}$, with female to male ratio of 1.2:1. The diagnosis was based on clinical - 85/193, home videos - 65/193 (33.6\%), interictal EEG - 28/193 (14.5\%), and video EEG - 15/193 (13\%). Based on morphology, NEPE were classified into syncope and other generalized paroxysms - 92/193 (47.7\%), movement disorders and other abnormal movements - 84/193 (43.5\%), oculomotor abnormalities 8/193 (4.1\%), and sleep disorders 9/193 (4.7\%). Based on system involvement, NEPE were classified into cardiac $3(1.6 \%)$, vascular 10 (5.2\%), neurological 17 (8.8\%), respiratory 39 (20.2\%), psychology $40(20.7 \%)$, sleep related $9(4.7 \%)$, channelopathies $12(6.2 \%)$, and unclassified $63(32.6 \%)$. The most common diagnoses were breath holding spells 33/193 (17\%), psychogenic seizures 32/193 (16.6\%), and migraine 31/193 (16.1\%). Epilepsy and NEPE coexisted in 17/193 (8.8\%) cases. We discontinued antiepileptic drugs in 25/193 (13\%) cases. NEPE accounted for $9 \%$ of paroxysmal events, which is comparable with previous studies [2-4].

To conclude, NEPE account for important cause for paroxysmal events, and both epilepsy and NEPE can be present in the same child. The home video is useful in doubtful cases and EEG/video EEG are required in undetermined cases of NEPE. Correct diagnosis helped in discontinuation of antiepileptic drugs. Most common NEPE were breath-holding spells, psychogenic seizures, and migraine.

\section{Declarations}

Conflict of Interest None.

\section{References}

1. Baslet G. Psychogenic non-epileptic seizures: a model of their pathogenic mechanism. Seizure. 2011;20:1-13.

2. Gowda VK, Amoghimath R, Benakappa N, Shivappa SK. Spectrum of nonepileptic paroxysmal events in children from southernIndia. J Neurosci Rural Pract. 2019;10:608-12.

3. Chen L, Knight EM, Tuxhorn I, Shahid A, Lüders HO. Paroxysmal non-epileptic events in infants and toddlers: a phenomenologic analysis. Psychiatry Clin Neurosci. 2015;69:351-9.

4. Kutluay E, Selwa L, Minecan D, Edwards J, Beydoun A. Nonepileptic paroxysmal events in a pediatric population. Epilepsy Behav. 2010;17:272-5.

Publisher's Note Springer Nature remains neutral with regard to jurisdictional claims in published maps and institutional affiliations.

Vykuntaraju K. Gowda

drknvraju08@gmail.com

1 Department of Pediatric Medicine, Indira Gandhi Institute of Child Health, Bangalore, Karnataka, India

2 Department of Pediatric Neurology, Indira Gandhi Institute of Child Health, Bangalore, Karnataka 560029, India 